\title{
The Relevance of the Second Cesarean Delivery in the Reduction of Institutional Cesarean Delivery Rates
}

\author{
Michael F.E. Diejomaoha, ${ }^{a}$ Waleed Al-Jassar ${ }^{a, b} \quad Z^{2}$ ainab Bello ${ }^{b}$ \\ Kavitha Karunakaran ${ }^{\mathrm{b}}$ Asiya Mohammed ${ }^{\mathrm{a}}$ \\ a Department of Obstetrics and Gynecology, Faculty of Medicine, Kuwait University, Safat, Kuwait; ${ }^{b}$ Department of \\ Obstetrics and Gynecology, Maternity Hospital, Safat, Kuwait
}

\section{Significance of the Study}

- In this study, a high primary cesarean delivery rate was reported, which could lead to future cesarean deliveries; the high incidence of repeat cesarean delivery commences with the second cesarean, further elevating institutional rates. This study highlights recommendations for the reduction of the second cesarean and ultimately, overall institutional cesarean delivery rates.

\section{Keywords}

Cesarean section · Delivery · Maternal morbidity and mortality · Electronic fetal monitoring

\begin{abstract}
Objective: The cesarean delivery rate has increased worldwide. The aim of our study was to assess the events associated with the second cesarean deliveries in our institution. Subjects and Methods: All cesarean deliveries at the Maternity Hospital, Kuwait, from January 1 to December 31, 2013, were identified. A comparative study was undertaken on patients having their first and second cesarean deliveries. The social and clinical characteristics of these patients were extracted from our records and the antenatal, intrapartum, and postpartum course of the pregnancies and their outcomes documented. Results: During the study period, 10,586 deliv-
\end{abstract}

eries were recorded, including 3,676 cesarean deliveries, i.e., a cesarean delivery rate of $34.7 \%$. 840 of these patients were undergoing their first cesarean delivery (group A) and 607 patients were undergoing their second (group B); 484 patients from group $A$ and 341 patients from group $B$ with complete records were analyzed. Mean age (30.89 \pm 4.93 vs. $29.94 \pm 5.56$ years, $p=0.008)$, parity (1.49 \pm 1.22 vs. $0.98 \pm$ $1.60, p<0.0001)$, gestational age at delivery (38.12 \pm 2.61 vs. $37.66 \pm 3.11$ weeks, $p=0.02)$, and fetal birth weight $(3,211.60$ \pm 691.51 vs. $2,829.73 \pm 863.26 \mathrm{~g}, p<0.001$ ) were significantly higher in group $B$ than in group A. $53.2 \%$ of the patients in group $B$ requested repeat cesarean delivery, their second cesarean. The rate of maternal morbidity was low. Conclusions: The incidence of repeat cesarean delivery in group $B$ is high, and its reduction should contribute to a lowering of the overall cesarean delivery rate.

(c) 2018 The Author(s)

Published by S. Karger AG, Basel

\begin{tabular}{ll}
\hline KARGER & $\begin{array}{l}\text { @ } 2018 \text { The Author(s) } \\
\text { Published by S. Karger AG, Basel }\end{array}$ \\
$\begin{array}{l}\text { Openger } \\
\text { E-Mail karger@karger.com }\end{array}$ & $\begin{array}{l}\text { This is an Open Access article licensed under the Creative Commons } \\
\text { Attribution-NonCommercial-4.0 International License (CC BY-NC) } \\
\text { www.karger.com/mpp }\end{array}$ \\
$\begin{array}{l}\text { (http://www.karger.com/Services/OpenAccessLicense), applicable to } \\
\text { the online version of the article only. Usage and distribution for com- } \\
\text { mercial purposes requires written permission. }\end{array}$
\end{tabular}

Prof. Michael F.E. Diejomaoh

Department of Obstetrics and Gynecology

Faculty of Medicine, Kuwait University

PO Box 24923, Safat 13110 (Kuwait)

E-Mail michaeldiejo@ hotmail.com 


\section{Introduction}

The incidence of cesarean delivery has increased in Kuwait and worldwide; in some maternal age groups, the increase in cesarean delivery has been quite high, with rates increasing to $49.5 \%$ in women aged $40-54$ years [ 1 , $2]$. The overall rate of cesarean section has been increasing in the USA, reaching $32.8 \%$ in 2011 [3-5]. Cesarean delivery rates increased from 5 to $31 \%$ between 1970 and 2007 [6-8], and they increased by 60\% between 1996 and 2009 [4]. Various reasons have been suggested for this rising rate including increasing maternal age, increasing number of births amongst nullipara, the use of electronic fetal monitoring, ready resort to cesarean section for breech deliveries and dropping incidence of operative vaginal deliveries including forceps and vacuum deliveries $[5,6,9-11]$. Efforts have been initiated to reduce the cesarean delivery rates with some positive results $[5,6]$. Adverse pregnancy outcome has been linked to increasing maternal age. One such adverse event has been the increased rate of cesarean deliveries which has been reported in women aged 35 years and older $[2,12-16]$; cesarean delivery in the USA increased from 30.2\% in 1996 to $49.5 \%$ in 2010 [2], and in Kuwait, the cesarean delivery rate in women aged 40 years and over was 31\% in 2006 [14].

Another very important cause identified for the rising cesarean delivery rate is the declining incidence of vaginal birth after cesarean delivery (VBAC) in many institutions and many countries including Kuwait [1, 3, 5, 6, 17-19]. Decreasing VBAC rates and rising primary cesarean section rates have contributed to the rising cesarean section rate in the USA $[3,6]$. Generally, there is an inverse relationship of the VBAC rate and the incidence of primary cesarean section rate. Increasing the VBAC rate and decreasing the primary cesarean delivery rate are two important targets set by the Centre for Disease Control for their Healthy People 2020 goals [20]. This was an attempt to reduce the cesarean section rate in the USA.

It is pertinent to define primary cesarean section at this point. Women having their first cesarean delivery (irrespective of their parity) are said to be having a primary cesarean delivery $[5,21,22]$. It has been reported that $60 \%$ of cesarean deliveries in the USA are primary cesarean sections [22], and after a primary cesarean delivery, a patient has only about $10 \%$ chance of vaginal birth in subsequent deliveries [22]. It is therefore extremely important that the decision for the primary cesarean section should be well justified and such a decision should be taken at the highest possible level as this has very important implications for the future obstetric performance of such patients. Efforts made to reduce overall (institutional, national and international) cesarean delivery rates should focus on primary cesarean sections [23].

The decision to embark on VBAC and the initiation and conduct of VBAC are extremely important if the objective of reducing institutional cesarean section is to be achieved. Refusal by the patient to embark on VBAC could have major consequences. The decision to embark on primary cesarean section and the successful subsequent VBAC (in future pregnancies) or a second cesarean section (if VBAC fails or is rejected) are crucial essential steps in the overall attempts to reduce institutional, national, international and worldwide cesarean delivery rates. VBAC has its own consequences and maternal and neonatal effects including ruptured uterus, other maternal injuries, cerebral palsy, and neonatal death, depending on the conduct of VBAC and its management.

The objective of our study was to assess the events associated with the second cesarean section in our institution.

\section{Subjects and Methods}

This was a 1-year retrospective study. All patients undergoing cesarean delivery at the Maternity Hospital, Kuwait, from January 1 through December 31, 2013, were identified. The Maternity Hospital, Kuwait, is the most significant tertiary obstetric care center in Kuwait, and most of the complicated obstetric cases are usually referred to this hospital. The patients who were undergoing their first cesarean delivery (primary cesarean) were identified and they constituted group A. The patients who were undergoing their second cesarean delivery were identified as group B. A comparative study of both groups was undertaken. The social biographical data of both groups were extracted from the available records in the department. The data on the obstetric history of the index pregnancy, and the past obstetric, gynecological, medical and surgical history were extracted from the records of the hospital. The antenatal, intrapartum and postpartum events were also obtained from the available records.

The decision for the cesarean delivery was taken at the highest level (usually by the Consultant Obstetrician and Gynecologist in charge of the case or on duty and/or assisted by the Senior Registrar; Senior Registrars have completed full training in the specialty and have achieved the specialist qualification approved by the department). All patients for cesarean deliveries were subjected to a full comprehensive consent approved by the department and all operations were performed under epidural/spinal analgesia and occasionally, general anesthesia was administered.

The timing and indications for the cesarean deliveries were carefully established. The maternal and perinatal outcome as documented was obtained from the data available. This study was approved by the Departmental Research Committee. All procedures were in accordance with ethical standards of the institution and 
Table 1. Clinical characteristics of the study population

\begin{tabular}{lccc}
\hline Event & $\begin{array}{l}\text { Group A } \\
(n=484)\end{array}$ & $\begin{array}{l}\text { Group B } \\
(n=341)\end{array}$ & $p$ value \\
\hline Age, years & $29.94 \pm 5.56$ & $30.89 \pm 4.93$ & $0.008^{\mathrm{a}}$ \\
Parity & $0.98 \pm 1.56$ & $1.49 \pm 1.22$ & $<0.0001^{\mathrm{a}}$ \\
Kuwaiti & $11(22.5)$ & $45(13.2)$ & - \\
Non-Kuwaiti & $38(77.5)$ & $296(86.8)$ & - \\
Gestational age at delivery, weeks & $37.66 \pm 3.11$ & $38.12 \pm 2.61$ & $0.02^{\mathrm{a}}$ \\
Fetal birth weight, g & $2,829.73 \pm 863.26$ & $3,211.60 \pm 691.51$ & $<0.0001^{\mathrm{a}}$ \\
\hline
\end{tabular}

Data are expressed as mean \pm standard deviation or as $n(\%)$. ${ }^{a}$ Significant.

with the 1964 Helsinki Declaration and its later amendments or comparable ethical standards. All the information collected were recorded on prepared forms and the data were subjected to statistical analysis. All the data were analyzed using the SPSS version 24 . Statistical analysis was performed using the $\chi^{2}$ test, Fisher exact $t$ test, and the Student $t$ test. $p$ values $\leq 0.05$ were regarded as significant.

\section{Results}

During the period of the study, there was a total of 10,586 deliveries including cesarean deliveries. 3,676 cesarean deliveries were performed during that period, giving a cesarean delivery rate of $34.7 \% .840$ patients were having their first cesarean delivery (primary cesarean delivery) and they constituted group A, leading a primary cesarean delivery rate of $22.9 \% .607$ patients were undergoing their second cesarean delivery and they constituted group B in the study, leading to a second cesarean delivery rate of 16.5\%. 484 patients from group A and 341 from group B had complete records from the data we had collected and they formed the basis of this study and were further analyzed.

The mean age $(29.4 \pm 5.56$ vs. $30.89 \pm 4.93$ years, $p=$ $0.0083)$ and mean parity ( $0.98 \pm 1.60$ vs. $1.49 \pm 1.23, p<$ 0.0001 ) were significantly higher in group $\mathrm{B}$ patients (Table 1). The gestational age at delivery $(37.66 \pm 3.11 \mathrm{vs.} 38$ weeks, $p=0.02)$ and fetal birth weight $(2,829 \pm 863.26$ vs. $3,211.6 \pm 691.51 \mathrm{~g}, p<0.0001)$ were also significantly higher in group B (Table 1). There was no difference in the percentages of Kuwaitis and non-Kuwaitis in the study groups. Non-Kuwaitis included non-Kuwaiti Arabs, Indians, Filipinos, Bangladeshi, Pakistanis, and other varied ethnic nationalities.

The patients presented with varied past medical and obstetric disorders as depicted in Table 2. Apart from di-
Table 2. Past medical and obstetrics history

\begin{tabular}{lrc}
\hline Event & Group A & Group B \\
\hline Diabetes mellitus (type 1/GDM) & $48(9.9)$ & $32(9.4)$ \\
Hypothyroidism & $13(2.7)$ & $7(2.1)$ \\
Hypertension & $8(1.7)$ & $3(0.9)$ \\
Bronchial asthma & $7(1.4)$ & $5(1.5)$ \\
PIH & - & $10(2.9)$ \\
Sickle cell anemia & $1(0.2)$ & - \\
Mitral valve prolapse & $1(0.2)$ & - \\
Cholestasis & $3(0.6)$ & - \\
Arthritis & $2(0.4)$ & - \\
Cervical cerclage $^{\mathrm{a}}$ & $1(0.2)$ & $1(0.3)$ \\
\hline
\end{tabular}

All data expressed as $n$ (\%). GDM, gestational diabetes; PIH, pregnancy-induced hypertension. ${ }^{\mathrm{a}}$ Event in the current pregnancy.

abetes mellitus, a fairly highly prevalent disorder in our subregion, the incidences of other medical/obstetric disorders were rather low, and none of the data achieved statistical significance.

The patients in both study groups presented with a variety of obstetric complications usually prevalent in the obstetric population of the patients at the Maternity Hospital, Kuwait. These obstetric complications included pregnancy-induced hypertension (gestational hypertension, 6.4 vs. $3.5 \%$ ), diabetes mellitus (type 1 diabetes and

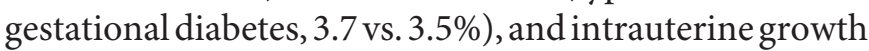
restriction ( 5.4 vs. $2.9 \%$ ); preterm labor ( 3.9 vs. $0.6 \%, p=$ 0.002 ), premature rupture of membranes (5.6 vs. $1.8 \%$, $p=0.006$ ), and antepartum hemorrhage ( 3.1 vs. $0.9 \%, p=$ 0.049 ) were more significantly reported in group A (Table $3)$. Induction of labor was more frequently performed in group A patients (25.8 vs. $7.0 \%, p<0.0001)$ and prostaglandin E2 vaginal pessaries were the most preferred method of induction in group A patients. 
Table 3. Antenatal complications and events related to labor

\begin{tabular}{|c|c|c|c|}
\hline Event & Group A & Group B & $p$ value \\
\hline \multicolumn{4}{|l|}{ Antenatal complications } \\
\hline PIH & $31(6.4)$ & $12(3.5)$ & 0.07 \\
\hline Diabetes mellitus & & & \\
\hline (type 1/GDM) & $18(3.7)$ & $12(3.5)$ & 1.00 \\
\hline Severe PE & $4(0.8)$ & & \\
\hline PROM & $27(5.6)$ & $6(1.8)$ & $0.006^{\mathrm{a}}$ \\
\hline Preterm labor & $19(3.9)$ & $2(0.6)$ & $0.002^{\mathrm{a}}$ \\
\hline IUGR & $26(5.4)$ & $10(2.9)$ & 0.11 \\
\hline $\mathrm{APH}$ & $15(3.1)$ & $3(0.9)$ & $0.049^{\mathrm{a}}$ \\
\hline \multicolumn{4}{|l|}{ Events related to labor } \\
\hline Spontaneous labor & $155(32.0)$ & $70(20.5)$ & $0.0004^{\mathrm{a}}$ \\
\hline Induced labor (IOL) & $125(25.8)$ & $24(7.0)$ & $<0.0001^{\mathrm{a}}$ \\
\hline \multicolumn{4}{|l|}{ Method of IOL } \\
\hline PGE2 & $68(14.1)$ & $8(2.3)$ & $<0.0001^{\mathrm{a}}$ \\
\hline Foley's catheter & $29(6.0)$ & $15(4.4)$ & 0.39 \\
\hline Syntocinon - infusion & $45(9.3)$ & $16(4.7)$ & $0.018^{\mathrm{a}}$ \\
\hline
\end{tabular}

Data expressed as $n$ (\%). IUGR, intrauterine growth restriction; $\mathrm{PE}$, preeclampsia; $\mathrm{PIH}$, pregnancy-induced hypertension; PROM, premature rupture of membranes; PGE2, prostaglandin pessaries; $\mathrm{APH}$, antepartum hemorrhage. ${ }^{\text {a }}$ Significant.

Table 4. Indications for cesarean section

\begin{tabular}{|c|c|c|c|}
\hline Indications for cesarean section & Group A & Group B & $p$ value \\
\hline Failure to progress in labor & $131(27.1)$ & $67(19.7)$ & $0.007^{\mathrm{a}}$ \\
\hline $\begin{array}{l}\text { Nonreassuring fetal status } \\
\text { (fetal distress) }\end{array}$ & $114(23.6)$ & $32(9.5)$ & $<0.0001^{\mathrm{a}}$ \\
\hline Breech presentation & $67(13.8)$ & $19(5.5)$ & $<0.0001^{\mathrm{a}}$ \\
\hline $\mathrm{PE} /$ severe $\mathrm{PE}$ & $13(2.7)$ & $4(1.2)$ & 0.14 \\
\hline Twin pregnancy & $28(5.8)$ & $3(0.9)$ & $0.0001^{\mathrm{a}}$ \\
\hline Placenta previa & $18(3.7)$ & $4(1.2)$ & $0.027^{\mathrm{a}}$ \\
\hline Refused VBAC & & $181(53.1)$ & \\
\hline IUGR & $8(1.7)$ & $1(0.2)$ & 0.08 \\
\hline GDM & $4(0.8)$ & $2(0.6)$ & 1.00 \\
\hline Brow presentation & $5(1.03)$ & & \\
\hline Transverse lie & $11(2.3)$ & $7(2.1)$ & 1.00 \\
\hline Cephalopelvic disproportion & $5(1.01)$ & $2(0.6)$ & 0.70 \\
\hline
\end{tabular}

Data expressed as $n$ (\%). GDM, gestational diabetes mellitus; IUGR, intrauterine growth restriction; PE, preeclampsia; VBAC, vaginal delivery after cesarean section. ${ }^{\text {a }}$ Significant.

The indications for the primary and secondary cesarean deliveries as performed in groups A and B are as laid out in Table 4. Failure to progress in labor (27.1 vs. 9.5\%, $p=0.007)$, nonreassuring fetal status (23.6 vs. $9.5 \%, p<$ $0.0001)$, breech presentation ( 13.8 vs. $5.5 \%, p<0.0001)$, twin pregnancy (5.8 vs. $0.9 \%, p=0.0001)$, and placenta praevia ( 3.7 vs. $1.2 \%, p=0.027$ ) were the most frequent indications for cesarean delivery and these were more significantly prevalent in group A patients. It is significant to note that cephalopelvic disproportion was the least prevalent indication for cesarean delivery. $53.2 \%$ of the patients in group B who had primary cesarean section previously and were appropriately counseled for vaginal delivery refused to undergo vaginal delivery and decided to undergo another cesarean delivery, i.e., their secondary cesarean delivery. The VBAC rate, calculated by dividing the number of women scheduled for VBAC who successfully delivered vaginally by the total number of women with previous cesarean delivery, was $10.6 \%$. The counseling of the patients for VBAC was usually undertaken by senior obstetric staff during the antenatal period of these patients, well before the onset of labor.

One patient in group B had a ruptured uterus and another had cesarean hysterectomy due to primary postpartum hemorrhage caused by placenta praevia/accreta; this gave a maternal morbidity rate of $0.1 \%$. There were no maternal deaths and the neonatal outcome was satisfactory.

\section{Discussion}

The overall cesarean delivery rate reported in this study $(34.7 \%)$ is high, although it is comparable to the high rate of $32.7 \%$ reported for the USA in 2013 and quoted above $[3-5,24,25]$. This high rate of cesarean delivery at the Maternity Hospital, Kuwait, has been a source of concern for the management and senior obstetricians, and efforts are being implemented to reduce this high rate.

In the current study, the incidence of primary cesarean section was $22.9 \%$, and this is quite high and comparable to the rate of total primary cesarean delivery of $21.5 \%$ for singleton pregnancies reported for 38 states in the USA as reviewed in 2012 [21]; the primary cesarean section rate in some states was higher, and rates of $26.9 \%$ were reported in the states of Florida and Louisiana [21]. It is pertinent to state that the primary cesarean section rate reported in the current study is for singleton and multiple pregnancies. The incidence of cesarean deliveries for multiple pregnancies is usually higher than for singleton pregnancies, although the number of multiple pregnancies included in the current study is rather small. The significance of this high primary cesarean delivery rate reported in this study is its contribution to the overall incidence of cesarean delivery rate in the institution, since, as 
previously stated, a patient who has had a primary cesarean delivery has a $10 \%$ chance of vaginal birth in subsequent deliveries [22]. With such a high incidence of primary cesarean delivery in the current study, it is quite conceivable that this will ultimately contribute significantly to the already high total cesarean delivery rate in our institution in Kuwait. The incidence of secondary cesarean delivery rate in the current study $(16.5 \%)$ is much lower than the rate of primary cesarean delivery as stated above, in spite of the findings that the maternal age, gestational age, and fetal birth weight are significantly higher in the group of patients undergoing secondary cesarean delivery. These are factors which will usually contribute towards a higher cesarean delivery rate. As previously stated, the increasing rate of cesarean deliveries has been associated with increasing maternal age $[2,12-16]$.

Cesarean sections (elective/emergency) are known to be associated with maternal and neonatal morbidities and they can also lead to maternal and neonatal mortality. Birth by cesarean section has been linked to childhood morbidities including insulin-dependent diabetes mellitus [26], asthma [27, 28], and obesity [29, 30], although a more recent study [28] did not link obesity in offspring with cesarean delivery. Increasing number of cesarean deliveries in a patient (which will start from a primary cesarean delivery and then repeat cesarean deliveries with no VBAC) has contributed to the rising incidences of placenta praevia/accreta with the additional consequences of primary postpartum hemorrhage, increased cesarean hysterectomy and other hazards including maternal morbidity and mortality. A recent study [31] showed that placenta praevia/accreta, a frequently reported cause of primary postpartum hemorrhage, was associated with a high risk of peripartum hysterectomy; other studies [32, 33] had also reported an increased risk of hysterectomy in patients with placental pathologies (which include placenta praevia/accreta) and cesarean sections.

In the group of patients who were scheduled for VBAC, $53.1 \%$ refused to undergo VBAC and had to undergo repeat cesarean delivery despite appropriate counseling; this would be their second cesarean delivery. The patients refused to undergo VBAC because they feared that a failed VBAC would eventually end up in another cesarean delivery after a long exhausting procedure of trial of failed vaginal delivery; they were also unwilling to undergo VBAC because they were aware that such failed procedures could lead to a ruptured uterus with the known dangers of maternal/perinatal morbidity and mortality. The VBAC rate as previously stated was $10.6 \%$, and this is comparable to the rates of $8.5-9.5 \%$ reported in some

Relevance of the Second Cesarean Delivery institutions and lower than the rate of $21-44 \%$ reported in some other institutions $[3,6]$. The rate of VBAC reported in our study is still unsatisfactorily low, and a further increase in the VBAC rate will certainly contribute towards a decline in the high cesarean rate in our institution.

The high percentage of refusal by patients to undergo VBAC as recorded above and thus resorting to another cesarean delivery, the secondary cesarean section, will contribute to more cesarean deliveries, and further to a higher total cesarean delivery rate in our institution. Many reasons which have been suggested as contributing towards the rising cesarean rate worldwide also apply to our institution.

Further training programs to ensure better utilization of electronic fetal monitoring by all doctors have been introduced in our department in the hope that such efforts could lead to a lowered cesarean delivery rate in spite of the knowledge that such end points may not be truly realized. There is a greater emphasis to ensure that breech presentations are more efficiently managed with the sole aim of reducing cesarean deliveries in these patients. Nonreassuring fetal status, another indication for cesarean delivery, has been more critically scrutinized before proceeding to cesarean delivery and although forceps deliveries are rather infrequently performed in our institution, more vacuum deliveries are being performed with a view to increasing the incidence of operative vaginal delivery. Increasing operative vaginal delivery is a strategy recently recommended by the American College of Obstetricians and Gynecologists and the Society of Maternal-Fetal Medicine as a strategy to lower the cesarean delivery rate [34]. A recent European study [35] aimed at reducing the incidence of anal sphincter tears in vaginal deliveries resulted in a reduction of cesarean delivery rates in that institution. Although adverse obstetric outcomes including increased cesarean deliveries have been associated with obesity and increasing maternal age, both risk factors being also prevalent in our community, our experience has demonstrated that the incidence of cesarean delivery was not significantly elevated in our patients aged 40 years and above [14].

One of the main outcomes in this study has been a rather high primary cesarean delivery rate, which then initiates the need for a decision on the subsequent delivery; only $10 \%$ of these patients who have undergone primary cesarean delivery may achieve a vaginal delivery subsequently [22]. These patients, after their primary cesarean delivery, will therefore inevitably proceed to a trial of VBAC, and since such a high proportion of our pa- 
tients refuse to undergo VBAC for reasons previously outlined, a second cesarean delivery will be performed which therefore adds to the high institutional cesarean delivery rate reported in this study. The decision to perform a second cesarean delivery will most likely lead to another cesarean delivery, and multiple repeat cesarean deliveries; this will ultimately lead to the complex interplay of factors leading to the various problems associated with multiple cesarean deliveries including placenta praevia/accreta, primary postpartum hemorrhage, cesarean hysterectomy, maternal morbidity, and probable maternal mortality [31-33]. This unfortunate trend is gradually increasing in our institution and causing great concern.

It can therefore not be emphasized enough that more aggressive steps should be established to drive down the high incidence of primary cesarean delivery, reduce the incidence of refusal to undergo VBAC and thus decrease the incidence of secondary cesarean delivery. One unfortunate development is the practice of patients requesting primary cesarean delivery rather than vaginal delivery for a variety of reasons. Such requests which are being accepted and implemented by some physicians will certainly contribute to a further increase in institutional cesarean delivery rates. Physicians should work harder at counseling such patients appropriately.
The limitations of this study include the fact that this was a retrospective study with all its associated disadvantages and further aggravated by the difficulty in locating the data of all our patients. This inadvertently led to a small study patient population.

In our study, we have reported a high incidence of primary cesarean delivery as well as a high incidence of patients' refusal to undergo VBAC, thus contributing to the increasing rate of secondary or repeat cesarean delivery. Reduction in both parameters, primary and secondary cesarean delivery rates as stated above, will contribute towards a reduction in the already high institutional cesarean delivery rate.

\section{Statement of Ethics}

All procedures performed in studies involving human participants were in accordance with ethical standards of the institution and/or national research committee and with the 1964 Helsinki Declaration and its later amendments or comparable ethical standards. Since this was a retrospective study, no formal consent was required.

\section{Disclosure Statement}

The authors declare that they have no conflicts of interest.

\section{References}

1 Martin JA, Hamilton BE, Ventura SJ, Osterman MJK, Wilson EC, Mathews TJ: Births: final data for 2010. Natl Vital Stat Rep 2012;61: $1-71$.

2 Timofeev J, Reddy UM, Huang CC, Driggers RW, Landy HJ, Laughon SK: Obstetric complications, neonatal morbidity, and indications for cesarean delivery by maternal age. Obstet Gynecol 2013;122:1184-1195.

3 Rosenstein MG, Kuppermann M, Gregorich SE, Cottrell EK, Caughey AB, Cheng YW: Association between vaginal birth after cesarean delivery and primary cesarean delivery rates. Obstet Gynecol 2013;122:1010-1017.

4 Hamilton BE, Martin JA, Ventura SJ: Births: Preliminary Data for 2011. National Vital Statistics Reports. Hyattsville, National Center for Health Statistics, 2012, vol 61, No 5.

5 Cunningham FG, Leveno KJ, Bloom SL, Spongy CY, Dushe JS, Hoffman BL, Casey BM, Sheffield JS: William Obstetrics, ed 24. New York, McGraw Hill Medical, 2014, pp 587-621.
6 Vaginal birth after previous cesarean delivery. Practice bulletin No 115. American College of Obstetricians and Gynecologists. Obstet Gynecol 2010;116:450-463.

7 Osterman MJK, Martin JA: Changes in cesarean delivery rates by gestational age: United States, 1996-2011. US Department of Health and Human Services. Centers for Disease Control and Prevention [CDC]. National Center for Health Statistics. NCHS Data Brief 2013;124:1-8.

8 Hamilton BE, Martin JA, Ventura SJ: Births: preliminary data for 2007. Natl Vital Stat Rep 2009;57:1-23.

9 Clark SL, Hankins GD: Temporal and demographic trends in cerebral palsy - fact and fiction. Am J Obstet Gynecol 2003;188:628-633.

10 Lee HC1, El-Sayed YY, Gould JB: Population trends in cesarean delivery for breech presentation in the United States, 1997-2003. Am J Obstet Gynecol 2008;199:59.e1-e8.

11 Goetzinger KR, Macones GA: Operative vaginal delivery: current trends in obstetrics. Womens Health (Lond) 2008;4:281-290.
12 Bianco A, Stone J, Lynch L, Lapinski R, Berkowitz G, Berkowitz RL: Pregnancy outcome at age 40 and older. Obstet Gynecol 1996:87:917-922.

13 Cleary-Goldman J, Malone FD, Vidaver J, Ball RH, Nyberg DA, Comstock CH, et al: Impact of maternal age on obstetric outcome. Obstet Gynecol 2005;105:983-990.

14 Diejomaoh MF, Shamali IA, Al-Kandari F, Al-Qenae M, Mohd AT: The reproductive performance of women at 40 years and over. Eur J Obstet Gynecol Reprod. Biol 2006;126: 33-38.

15 Paulson RJ, Boostanfar R, Saadat P, Mor E, Tourgeman DE, Slater CC, Francis MM, Jain JK: Pregnancy in the sixth decade of life: obstetric outcomes in women of advanced reproductive age. JAMA 2002;88:2320-2323.

16 Martin JA, Hamilton BE, Ventura SJ, Osterman MJK, Wilson EC, Mathews TJ: Births: final data for 2010. Natl Vital Stat Report 2012; 61:1-71.

17 Hurley V, Brownlee S: Elective Child Birth Procedures in California: A Close-Up of Geographic Variation. Sacramento, California Health Care Foundations, 2011. 
18 Boyle A, Reddy UM: Epidemiology of cesarean delivery: the scope of the problem. Semin Perinatol 2012;36:308-314.

19 MacDorman M, Declercq E, Manacker F: Recent trends and patterns in Cesarean and vaginal birth after Cesarean (VBAC) Deliveries in the United States. Clin Perinatol 2011;38: 179-192.

20 US Department of Health and Human Services; Office of Disease Prevention and Health Promotion: Healthy People 2020. 2013. http://healthypeople.gov/2020/topicsobjective2020/objective.list.aspx?topicID $=26$ (accessed April 25, 2013).

21 Osterman MJK, Martin JA: Primary cesarean delivery rates by state: results from the revised birth certificate, 2006-2014. Natl Vital Stat Rep 2014;63:1-11.

22 Data from the 2012 final natality file (unpublished). Hyattsville, MD: National Center for Health Statistics. http://www.cdc.gov/nchs/ data_access/vitalstatisticsonline.htm.

23 US Department of Health and Human Services, Office of Disease Prevention and Health Promotion: Healthy People 2020: Maternal, Infant, and Child Health. 2013. http://www. healthpeople.gov/2020/topicsobjectives2020/ overview.aspx?topicID=26 (accessed July 31 , 2013).
24 Wilson-Leedy JG, DiSilvestro AJ, Repke JT, Pauli JM: Reduction in the Cesarean delivery rate after obstetric care consensus guideline implementation. Obstet Gynecol 2016;128: 145-152.

25 Rouse DJ, Owen J, Hauth JC: Active-phase labor arrest: oxytocin augmentation for at least 4 hours. Obstet Gynecol 1999;93:323-328.

26 Cardwell CR, Stene LC, Joner G, Cinek O, Svensson J, Goldacre MJ, et al: Cesarean section is associated with an increased risk of child - onset type 1 diabetes mellitus; a metaanalysis of observational studies. Diabetologia 2008;51:726-735.

27 Roduit C, Scholtens S, de Jongste JC, Wijga AH, Gerritsen J, Postma DS, et al: Asthma at 8 years of age in children born by caesarean section. Thorax 2009;64:107-113.

28 Mamun AA, Sutharsan R, O'Callaghan M, Williams G, Najman J, McIntyre HD, Callaway $\mathrm{L}$ : Cesarean delivery and the long-term risk of offspring obesity. Obstet Gynecol 2013;122:1176-1183.

29 Goldani HA, Bettiol H, Barbieri MA, Silva AA, Agranonik M, Morais MB, Goldani MZ: Cesarean delivery is associated with an increased risk of obesity in adulthood in a Brazilian birth cohort study. Am J Clin Nutr 2011;93:1344-1347.
30 Li HT, Zhou YB, Liu JM: The impact of cesarean section on offspring overweight and obesity: a systematic review and meta-analysis. Int J Obes (Lond) 2013;37:893-899.

31 Huque S, Roberts I, Fawole B, Chaudhri R, et al: Risk factors for peripartum hysterectomy among women with postpartum haemorrhage: analysis of data from the WOMAN trial. BMC Pregnancy Childbirth 2018;18:186194

32 van den Akker T, Brobbel C, Dekkers OM, Bloemenkamp KW: Prevalence, indications, and outcomes of emergency peripartum hysterectomy worldwide: a systematic review and meta-analysis. Obstet Gynecol 2016;128:281294

33 Bodelon C, Bernabe-Ortiz A, Schiff MA, Reed SD: Factors associated with peripartum hysterectomy. Obstet Gynecol 2010;114:15-123.

34 Caughey AB, Cahill AG, Guise JM, et al: Safe prevention of the primary cesarean delivery. Am J Obstet Gynecol 2014;210:17-93.

35 Pirhonen J, Samuelsson E, Pirhonen T, et al Interventional program to reduce both the incidence of anal sphincter tears and rate of cesarean sections. Eur J Obstet Gynecol Reprod Biol 2018;223:56-59. 